\title{
Eutrophic water or fertile sediment: which is more important for the growth of invasive aquatic macrophyte Myriophyllum aquaticum?
}

\author{
Bingchang Tan ${ }^{1,2}, \mathrm{Hu} \mathrm{He}^{1}$, Jiao $\mathrm{Gu}^{1,2}$ and Kuanyi $\mathrm{Li}^{1,3,4, *}$ \\ ${ }^{1}$ State Key Laboratory of Lake Science and Environment, Nanjing Institute of Geography and Limnology, Chinese Academy of \\ Sciences, Nanjing, 210008, PR China \\ ${ }^{2}$ University of Chinese Academy of Sciences, Beijing 100049, PR China \\ ${ }^{3}$ Sino-Danish College, University of Chinese Academy of Sciences, Beijing 100049, PR China \\ ${ }^{4}$ College of Fisheries and Life Science, Shanghai Ocean University, Shanghai 201306, PR China
}

\begin{abstract}
Invasive macrophyte Myriophyllum aquaticum is capable of assimilating nutrients from both the sediments and the water column. However, which is the major source of nutrients supporting $M$. aquaticum growth under various nutrient regimes has not been well documented. Here we conducted a twofactorial outdoor experiment (three levels of nutrient loading and two types of sediments) from 23 May to 27 June 2016, to assess $M$. aquaticum responses to different nutrient levels in the water column and the sediment. Results showed that concentrations of total nitrogen, total phosphorus and chlorophyll $a$ in the water column increased in the treatment groups, but decreased slightly in the control group (nutrient-poor sediment and no nutrient addition). Sediment type had a significant effect on the growth M. aquaticum, while there were no significant effects of nutrient loading levels and the interactions between the two factors. Mean relative growth rate, mean plant height, mean stem diameter, the number of lateral branches and roots in the nutrient-rich sediment treatments were 1.6, 1.2, 1.6, 3.2 and 5.9 folds greater than in the nutrient-poor sediment treatments, respectively. These results suggest that nutrient-rich sediment has a positive effect on the growth of $M$. aquaticum. This study reveals possible expansion mechanism of the exotic M. aquaticum in China, and may provide valuable information on the ecological restoration of eutrophic freshwaters.
\end{abstract}

Keywords: Myriophyllum aquaticum / nutrient level in water column / sediment type / growth characteristics / expansion mechanism

Résumé - Eau eutrophe ou sédiment fertile: quel est le plus important pour la croissance du macrophyte envahissant Myriophyllum aquaticum? Le Myriophyllum aquaticum est capable d'assimiler les nutriments des sédiments et de la colonne d'eau. Toutefois, les sources principales de nutriments qui soutiennent la croissance du M. aquaticum dans divers régimes nutritionnels n'ont pas été bien documentées. Nous avons mené une expérience en extérieur à deux facteurs (trois niveaux de charge nutritive et deux types de sédiments) du 23 mai au 27 juin 2016, afin d'évaluer les réponses de $M$. aquaticum à différents niveaux nutritifs dans la colonne d'eau et les sédiments. Les résultats ont montré que les concentrations d'azote total, de phosphore total et de chlorophylle a dans la colonne d'eau augmentaient dans les groupes de traitement, mais diminuaient légèrement dans le groupe témoin (sédiments pauvres en éléments nutritifs et aucun ajout de nutriments). Le type de sédiments a eu un effet significatif sur la croissance du M. aquaticum, alors qu'il n'y a eu aucun effet significatif des niveaux de charge en éléments nutritifs et des interactions entre les deux facteurs. Le taux de croissance relatif moyen, la hauteur moyenne des plantes, le diamètre moyen des tiges, le nombre de branches latérales et de racines dans les traitements des sédiments riches en éléments nutritifs étaient respectivement de 1.6, 1.2, 1.6, 3.2 et 5.9 fois plus élevés que dans les traitements des sédiments pauvres en éléments nutritifs. Ces résultats suggèrent que les sédiments riches en nutriments ont un effet positif sur la croissance de M. aquaticum. Cette étude révèle un mécanisme possible de progression

\footnotetext{
*Corresponding author: kyli@niglas.ac.cn
} 
du M. aquaticum exotique en Chine et pourrait fournir des informations précieuses sur la restauration écologique des eaux douces eutrophes.

Mots-clés : Myriophyllum aquatique / niveau de nutriments dans la colonne d'eau / types de sédiments / caractéristiques de croissance / mécanisme d'expansion

\section{Introduction}

Aquatic macrophytes are an important component of the aquatic ecosystems (Fleming and Dibble, 2015). Their presence can reduce turbidity caused by disturbance of wind wave and benthic fish, both of which often lead to sediment resuspension. Furthermore, aquatic macrophytes can compete for nutrients with algae or release allelopathic substances harmful to algal growth that results in turbidity (Scheffer et al., 1993). However, the expansion of invasive aquatic plants may lead to ecosystem change by displacing native species (Brundu, 2014) and reduce biodiversity (Hussner et al., 2017).

Parrotfeather [Myriophyllum aquaticum (Vellozo) Verdcourt], an amphibious aquatic macrophyte, is indigenous to South America and has been introduced to many regions of the world (Thiébaut, 2007). Recently, M. aquaticum has been brought to China and established (Li and Changfu, 1996). The reasons for successful invasion are characteristic of rapid reproduction via fragmentation (Thiébaut and Martinez, 2015) and have a strong enduring ability to multifarious environment. This plant can grow well either with or without roots, which may give $M$. aquaticum competitive advantage over some nonnative species and expand quickly in a new environment (Xie et al., 2010). There have been reports on detrimental impacts by $M$. aquaticum including interference with fisheries in South Africa (Guillarmod, 1977). The introduction of M. aquaticum may also pose a potential risk to native aquatic plants in China (Xie et al., 2010).

Sediment is often considered the primary source of nutrients for rooted macrophytes in shallow lakes. A large amount of nitrogen $(\mathrm{N})$ and phosphorus $(\mathrm{P})$ required for $M$. aquaticum growth is also derived from sediments (Barko and Smart, 1986). However, some aquatic macrophytes with relatively less developed roots such as Hydrilla verticillata and floating aquatic weed such as Eichhornia crassipes assimilate significant amounts of nutrients directly from the water column (Zhang and Liu, 2011; Wang et al., 2013). Having two types of root forms (adventitious roots and underground roots) may give $M$. aquaticum two distinct growth forms (floating and rooting), which allow them use nutrients from both sediment and water column (Saunkaew et al., 2011). However, the relative importance of sediment and surface water under various nutrient levels has not been well documented.

Myriophyllum aquaticum has already been used as a means for ecological remediation in China. Excessive discharge of domestic sewage and livestock wastewater heavily loaded with $\mathrm{N}, \mathrm{P}$ and organic compounds have resulted in a growing number of rivers in many areas of China that have become deteriorated (Qu and Fan, 2010; Ning et al., 2014). Many studies demonstrated that M. aquaticum could survive in high N-loaded wastewater (Zhang et al., 2017) and reduce nutrient loads (Liu et al., 2016). Thus, M. aquaticum could potentially be an alternative restoration tool.
M. aquaticum were brought to China as ornamental plant and were widely planted in the shore zone that is characterized by lower levels of nutrients. However, a very high portion of the rivers are polluted in China as well as other countries. These rivers often have nutrient-rich sediments which could accelerate $M$. aquaticum growth and expansion. In the present study, a two-factor controlled experiment (water column nutrient level and sediment type) was conducted to investigate the effects of increasing nutrients in the water column and sediment type on the growth characteristics of $M$. aquaticum.

\section{Materials and methods}

\subsection{Experimental design}

An outdoor mesocosm experiment was conducted from 23 May to 27 June 2016 at the Taihu Laboratory for Lake Ecosystem Research Station, which is located in Meiliang Bay, one of the most eutrophic areas in the northern part of the Lake Taihu (Chen et al., 2003). The experiment units consisted of 12 polyethylene buckets (height $95 \mathrm{~cm}$, upper diameter $87 \mathrm{~cm}$, bottom diameter $76 \mathrm{~cm}$ ) with 10 culture pots (height $13.5 \mathrm{~cm}$, top diameter $17 \mathrm{~cm}$, bottom diameter $12 \mathrm{~cm}$ ) in each bucket. Each bucket was filled with lake water to a height of $50 \mathrm{~cm}$ of the bucket. The lake water was pre-filtered through a plankton net ( $64 \mu \mathrm{m}$ mesh size) to remove plankton and inorganic particles.

Experiment design included three levels of nutrient treatment: control (no nutrient addition); moderate nutrient loading $\left(130 \mu \mathrm{g} \mathrm{N} \mathrm{L}^{-1} \mathrm{~d}^{-1}, 5 \mu \mathrm{g} \mathrm{PL}^{-1} \mathrm{~d}^{-1}\right)$, which is the typical average daily nutrient loading to Lake Taihu (Kang et al., 2013); and high nutrient loading $\left(260 \mu \mathrm{g} \mathrm{N} \mathrm{L}^{-1} \mathrm{~d}^{-1}\right.$, $10 \mu \mathrm{g} \mathrm{P} \mathrm{L}^{-1} \mathrm{~d}^{-1}$ ). Two sediment treatments included nutrientrich and nutrient-poor sediment collected from Meiliang Bay (Tab. 1). There were four replicates in each treatment in a randomized complete block design.

Prior to experiment, both nutrient-rich and nutrient-poor sediments were dried, sieved (mesh size of $1.0 \mathrm{~mm}$ ) and stirred to remove coarse debris and mixed to ensure uniformity. Ten plastic culture pots were placed into each bucket, five containing nutrient-rich sediment and the other five containing nutrient-poor sediment to a depth of $10 \mathrm{~cm}$.

Experimental plants (M. aquaticum) with apical shoots were collected from Lake Taihu and grown in two outdoor polyethylene tanks filled with $50 \mathrm{~cm}$ depth of filtered lake water and $10 \mathrm{~cm}$ depth of sediment substrate $(1: 1$ mixture experimental nutrient-rich and nutrient-poor sediment) for seven days. A total of 360 apical, unbranched fragments from $M$. aquaticum with similar stem diameter $(0.3 \mathrm{~cm})$ were collected from the culture tanks. Each fragment was cut into equal lengths of $70 \mathrm{~cm}$ and measured for fresh weights. Three fragments were transplanted into each culture pot that was placed into the bottom of each bucket. During the experiment 
Table 1. Content $\left(\mathrm{mg} \mathrm{g}^{-1}\right.$, mean $\left.\pm \mathrm{SD}\right)$ of total nitrogen $(\mathrm{TN})$, total phosphorus (TP) and organic matter (OM) in two sediment types.

\begin{tabular}{lllll}
\hline Sediment type & TN & TP & OM & N \\
\hline Nutrient-rich & $1.38 \pm 0.282$ & $0.43 \pm 0.024$ & $15.9 \pm 0.187$ & 4 \\
Nutrient-poor & $0.54 \pm 0.096$ & $0.21 \pm 0.068$ & $3 \pm 0.208$ & 4 \\
\hline
\end{tabular}

period, water temperature varied between $19^{\circ} \mathrm{C}$ and $30^{\circ} \mathrm{C}$ and differed no more than $1{ }^{\circ} \mathrm{C}$ among the experiment buckets.

Over the 35-day experiment period, dissolved nutrients were added daily to each experimental bucket. Nitrogen and phosphorus were added as aqueous solutions of ammonium sulfate $\left[\left(\mathrm{NH}_{4}\right)_{2} \mathrm{SO}_{4}\right]$ and potassium dihydrogen phosphate $\left(\mathrm{KH}_{2} \mathrm{PO}_{4}\right)$, respectively. Dead branches floating on the surface of the water from each bucket were removed. Filtered lake water was added to each bucket daily to compensate for evaporation and to maintain a constant water level $(50 \mathrm{~cm})$ during the experiment.

\subsection{Sample collection}

Samplings were conducted on day 0 (before the first addition of nutrients), 7, 14, 21, 28 and 35 of the experiment period. One liter depth-integrated water sample was collected from each bucket using a water sampler (length $27.5 \mathrm{~cm}$, diameter $12.5 \mathrm{~cm}$ ) for chemical and biological analyses. Total $\mathrm{N}$ (TN) and total P (TP) in the water column were determined (Jin and Tu, 1990). Chlorophyll $a(\mathrm{Chl} a$ ) concentration was measured spectrophotometrically from matter retained on a $\mathrm{GF} / \mathrm{C}$ (Whatman) filter extracted over $24 \mathrm{~h}$ in a $90 \%(\mathrm{v} / \mathrm{v})$ acetone, and values were calculated without correction for phaeophytin (SEPA, 2002). One pot from each sediment type was taken out from each bucket, with a total of 24 pots collected at each sampling. The plants were removed from the pots and washed under running water. Relative growth rate, mean plant height, mean stem diameter, number of lateral branches and roots were measured. The relative growth rate $(R G R)$ was calculated as:

$$
R G R\left(\mathrm{mg} \mathrm{g}^{-1} \mathrm{~d}^{-1}\right)=1000 \times \ln \left(\frac{W_{2} / W_{1}}{D_{2}-D_{1}}\right),
$$

where $W_{1}(\mathrm{~g})$ and $W_{2}(\mathrm{~g})$ refer to total wet weight per pot at corresponding sampling days $D_{1}$ and $D_{2}$, respectively.

\subsection{Statistical analyses}

Paired $t$-tests were used to assess the differences in nutrient contents between the two types of sediment. Repeated measures analysis of variance (rANOVA) was applied to analyze time-series data, including TN, TP and Chl $a$ in the water column and relative growth rate, mean plant height, mean stem diameter, number of lateral branches and roots of M. aquaticum in each pot. Data were tested for normal distribution of residuals and homogeneity of variance to meet the assumptions of ANOVAs. Where necessary, data were $\log _{10}$ transformed prior to analysis. All statistical procedures were performed using SPSS version 21.0 (IBM Corporation, Somers, NY, USA).
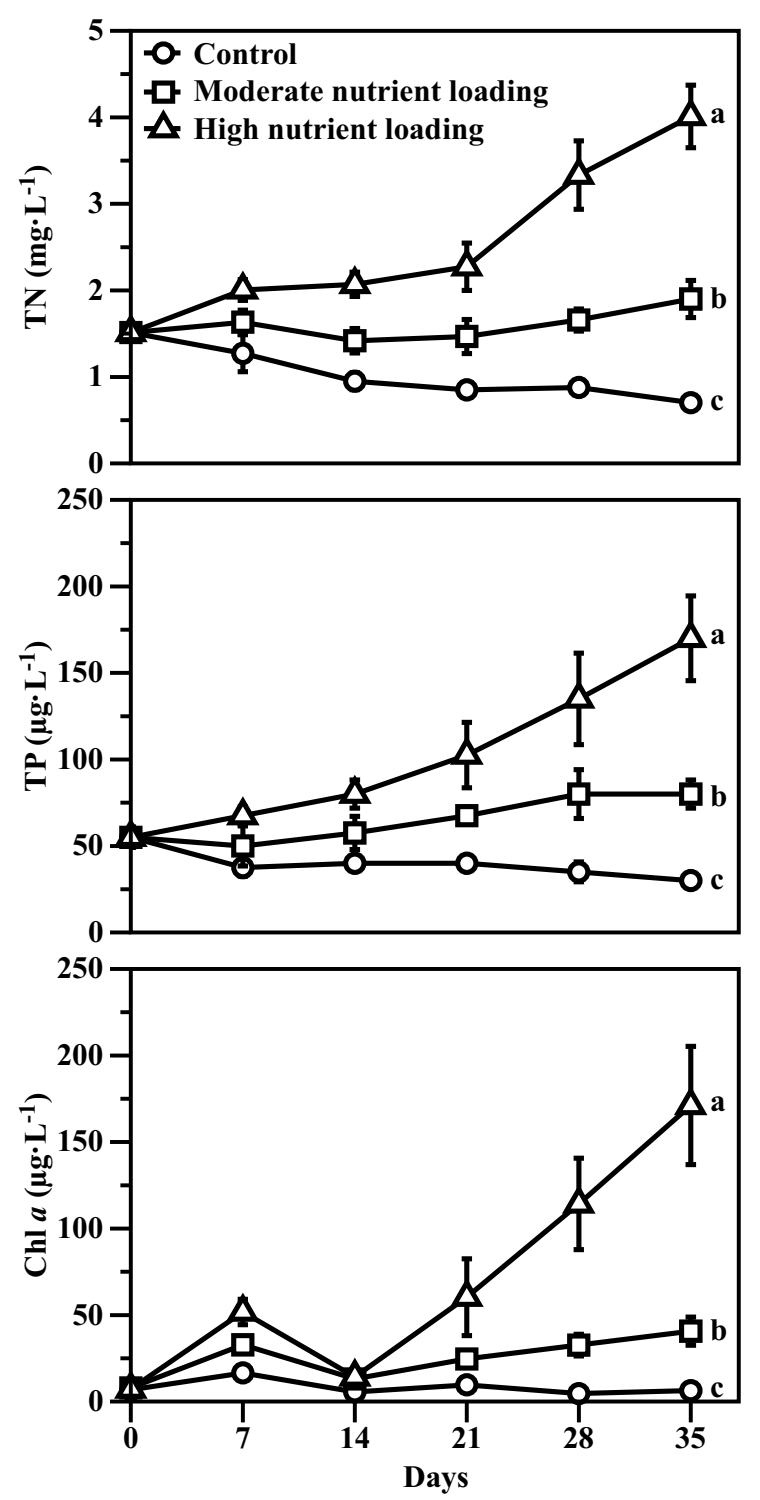

Fig. 1. Total nitrogen (TN), total phosphorus (TP) and Chlorophyll a (Chl a) content in various water-column nutrient combinations during the 35 day experiment. Values are means of the four replicates; Error bars represent one standard deviation. Treatments labeled sharing the same letters indicate no significant differences between treatments at $P>0.05$.

\section{Results}

\subsection{Changes of nutrient and $\mathrm{Chl}$ a concentrations in water column}

The treatments with nutrient loading had significant effects on several chemical and biological variables in the surface water of each treatment group (Fig. 1). The water column TN and TP in the nutrient treatments increased significantly over time and were significantly higher in the high nutrient loading treatment than the control and moderate nutrient loading treatment $(P<0.01)$. A slight decrease was observed in the control group over time. Mean $\mathrm{Chl} a$ concentration in high nutrient loading group was higher than the other groups $(P<0.01)$, while mean 


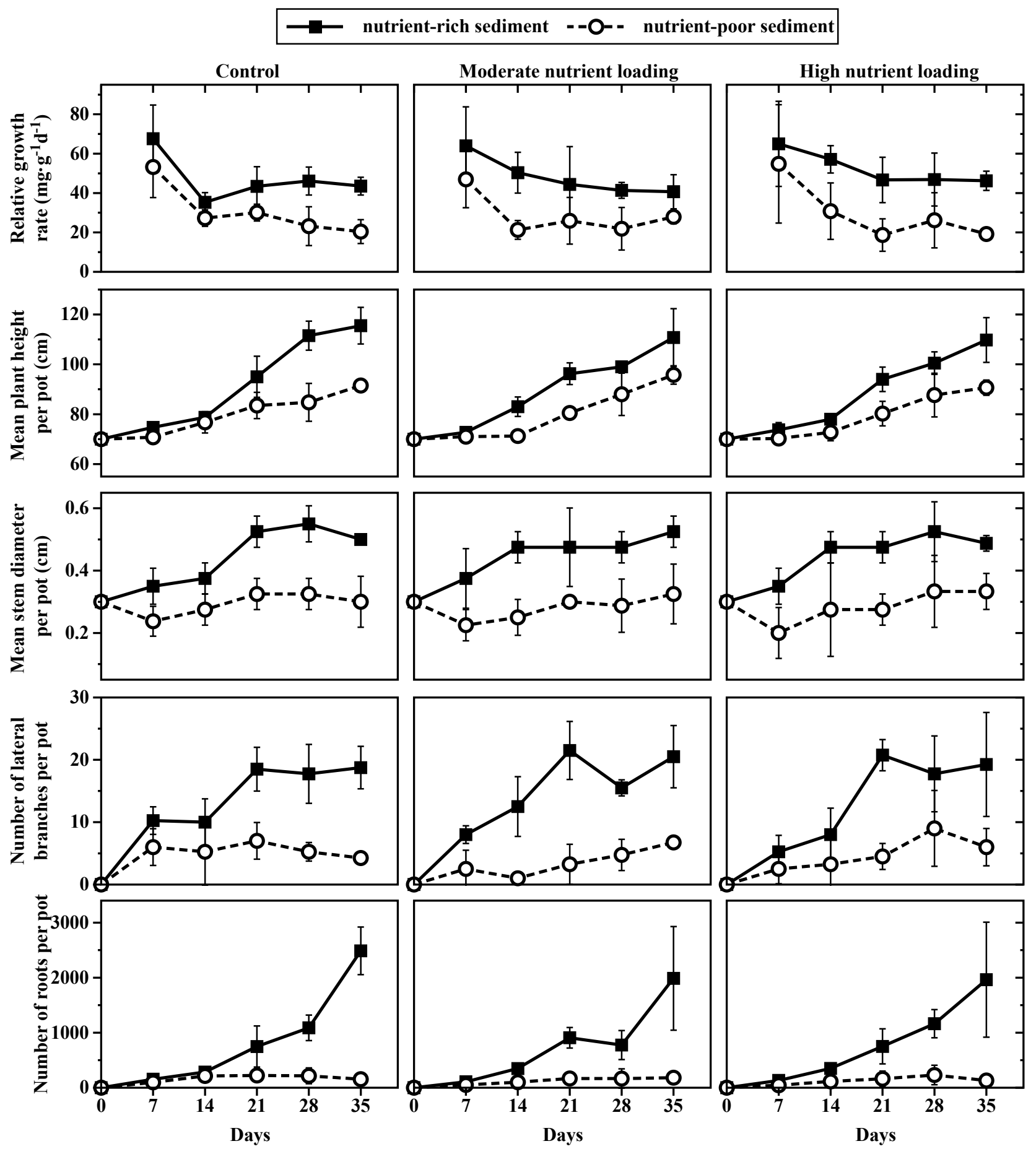

Fig. 2. Relative growth rate, plant height, stem diameter, the number of lateral branches and roots of M. aquaticum in various water-column nutrient combinations and sediment type (nutrient-rich and nutrient-poor sediment) during the 35 day experiment. Values are means of the four replicates; Error bars represent one standard deviation.

Chl $a$ concentration in the control group was significantly lower than that the moderate nutrient loading treatment $(P<0.05)$.

\subsection{Growth characteristics}

Relative growth rate displayed a trend of declines in all treatments and was 1.6 folds higher in the nutrient rich sediment than in the nutrient-poor sediment. However, the difference within same sediment type between nutrient loading treatment and the interactions between sediment types and nutrient loading were not significant (Fig. 2; Tab. 2). The mean plant height, mean stem diameter, the number of lateral branches and roots of $M$. aquaticum responded significantly to sediment type (Fig. 2; Tab. 2), and the values of all four 
Table 2. Summary of a two-way ANOVA results on morphological traits of M. aquaticum based on time-weighted data during the 35 day experiment period. Factors are external nutrient loading (ND) and sediment type (S); Bold values indicate statistical significance $(P<0.05)$.

\begin{tabular}{lllll}
\hline Growth index & Source & $d f$ & $F$ & $P$ \\
\hline \multirow{3}{*}{ Relative growth rate } & $\mathrm{ND}$ & 2 & 0.447 & 0.647 \\
& $\mathrm{~S}$ & 1 & 58.182 & $<\mathbf{0 . 0 0 1}$ \\
& $\mathrm{ND} \times \mathrm{S}$ & 2 & 0.543 & 0.590 \\
Mean plant height per pot & $\mathrm{ND}$ & 2 & 1.390 & 0.275 \\
& $\mathrm{~S}$ & 1 & 92.910 & $<\mathbf{0 . 0 0 1}$ \\
& $\mathrm{ND} \times \mathrm{S}$ & 2 & 0.538 & 0.593 \\
Mean stem diameter per pot & $\mathrm{ND}$ & 2 & 0.042 & 0.959 \\
& $\mathrm{~S}$ & 1 & 150.621 & $<\mathbf{0 . 0 0 1}$ \\
& $\mathrm{ND} \times \mathrm{S}$ & 2 & 0.160 & 0.853 \\
Number of lateral branches per pot & $\mathrm{ND}$ & 2 & 0.292 & 0.751 \\
& $\mathrm{~S}$ & 1 & 149.818 & $<\mathbf{0 . 0 0 1}$ \\
& $\mathrm{ND} \times \mathrm{S}$ & 2 & 1.117 & 0.349 \\
Number of roots per pot & $\mathrm{ND}$ & 2 & 1.996 & 0.369 \\
& $\mathrm{~S}$ & 1 & 127.716 & $<\mathbf{0 . 0 0 1}$ \\
& $\mathrm{ND} \times \mathrm{S}$ & 2 & 0.332 & 0.847 \\
\hline
\end{tabular}

variables were considerably higher in the nutrient-rich sediment than that in the nutrient-poor sediment (Tab. 2). Mean plant height, mean stem diameter, the number of lateral branches and roots of each pot in the nutrient-rich sediment treatments were 1.2, 1.6, 3.2 and 5.9 folds greater than in the nutrient-poor sediment, respectively. The increase in the values of all four variables typically began since the first sampling event on day 7 . Sediment type had a significant effect on the mean plant height, mean stem diameter and the number of lateral branches and roots (Tab. 2), while the effect of nutrient loading and interactions between the two factors were not significant (Tab. 2).

\section{Discussion}

Our study indicated that sediment type had a significant positive effect on the growth of M. aquaticum. Root uptake is the primary pathway for $\mathrm{N}$ and $\mathrm{P}$ when nutrient contents in sediment are greater than in the water column. Zhang et al. (2013) found that nutrient-rich sediments accelerated the growth of M. spicatum. In our study, we also found higher $R G R$ in fertile sediments and produced more branches than those in the nutrient-poor sediment. The high growth rate of $M$. aquaticum indicated by plant height and stem diameter in nutrient-rich sediment led to more propagules that facilitate the establishment of populations in newly invaded habitats. The production of roots acquired more nutrients from sediment to support plant growth (Wersal and Madsen, 2011) which is evident by the increased number of roots in nutrient-rich sediment than that in the nutrient-poor sediment in our study.

Our results indicated that nutrient addition to the water column had little effect on the growth of M. aquaticum, in either nutrient-rich or nutrient-poor sediment. Nutrients required by $M$. aquaticum could be obtained from the sediment almost entirely to meet the needs of growth. A small portion of nutrients in the water column may be assimilated via the shoot on the condition that nutrient concentrations in the water column is sufficiently high (Carignan, 1982). Zhang et al. (2017) showed that M. aquaticum could grow normally and removed $87.8 \%$ of $\mathrm{TN}$ in high N-loaded wastewater (TN: $\left.494.9 \mathrm{mg} \mathrm{L}^{-1}\right)$. Souza et al. (2013) showed 93.6\% TP reduction in polluted water (TP: $3.44 \pm 0.30 \mathrm{mg} \mathrm{L}^{-1}$ ) with the presence of with $M$. aquaticum. In this study, the ranges of water column TN and TP were 0.5 to $4.5 \mathrm{mg} \mathrm{L}^{-1}$ and 50 to $200 \mu \mathrm{g} \mathrm{L}^{-1}$, respectively, which were far lower than the reported surface water concentrations which stimulated active nutrient uptake (Souza et al., 2013; Zhang et al., 2017). The concentrations of TN and TP increased in the nutrient addition treatments, but a slight decrease was found in the control group in our experiment, likely as the consequence of nutrient uptake by of $M$. aquaticum.

Ecological mechanisms of invasion success in aquatic macrophytes include competition, enemy release evolution of increased competitive ability, mutualisms, invasion meltdown, novel weapons, allelopathy, phenotypic plasticity, naturalization of related species, empty niche, fluctuating resources, opportunity windows and propagule pressure (Fleming and Dibble, 2015). For example, fluctuating resources and opportunity windows are the mechanisms of $M$. aquaticum invasion process during the establishment phase (Fleming and Dibble, 2015). A potential invasion mechanism of $M$. aquaticum in eutrophic waters may be attributed to the sediment with considerable amounts of nutrients and organic matter (Asaeda et al., 2000) which may promote the survival, regeneration and colonization of $M$. aquaticum fragments in freshwaters (Thiébaut and Martinez, 2015). When M. aquaticum is used to manage malodorous black rivers, detached plant fragments will likely enter the receiving waters such as eutrophic lakes, thereby posting a potential ecological risk.

In conclusion, $M$. aquaticum could grow normally with increasing nutrient loading in eutrophic shallow lakes such as Lake Taihu. Since M. aquaticum rely mainly on nutrients from the sediments, nutrient-rich sediment may promote the growth of $M$. aquaticum. This study indicates that fertile sediment in eutrophic waters may be the main reason for rapid expansion of this exotic species. Therefore, reduction of nutrient-rich sediment may prevent overgrowth and expansion of $M$. aquaticum.

Acknowledgments. This research was supported jointly by the National Water Pollution Control and Management Technology Major Projects of China (2017ZX07203-005), the National Science Foundation of China $(31770509,41571086,31370477)$ and Key Projects of Chinese Academy of Sciences (KFZD-STS302-02).

\section{References}

Asaeda T, Trung VK, Manatunge J. 2000. Modeling the effects of macrophyte growth and decomposition on the nutrient budget in Shallow Lakes. Aquat Bot 68: 217-237.

Barko JW, Smart RM. 1986. Sediment-related mechanisms of growth limitation in submersed macrophytes. Ecology 67: 1328-1340.

Brundu G. 2014. Plant invaders in European and Mediterranean inland waters: profiles, distribution, and threats. Hydrobiologia 746: 61-79. 
Carignan R. 1982. An empirical model to estimate the relative importance of roots in phosphorus uptake by aquatic macrophytes. Can J of Fish Aquat Sci 39: 243-247.

Chen Y, Qin B, Teubner K, et al. 2003. Long-term dynamics of phytoplankton assemblages: Microcystis-domination in Lake Taihu, a large shallow lake in China. J Plankton Res 25: 445-453.

Fleming JP, Dibble ED. 2015. Ecological mechanisms of invasion success in aquatic macrophytes. Hydrobiologia 746: 23-37.

Guillarmod AJ. 1977. Myriophyllum, an increasing water weed menace for South Africa.S Afr J sci 73: 89-90.

Hussner A, Stiers I, Verhofstad MJJM, et al. 2017. Management and control methods of invasive alien freshwater aquatic plants: a review. Aquat Bot 136: 112-137.

Jin XC, Tu QY. 1990. The standard methods for observation and analysis in Lake eutrophication, 2nd ed. Beijing (in Chinese): Chinese Environmental Science Press.

Kang Y, Song X, Liu Z. 2013. Sediment resuspension dampens the effect of nutrient inputs on the phytoplankton community: a mesocosm experiment study. Hydrobiologia 710: 117-127.

Li ZY, Changfu H. 1996. New materials of the genus Myriophyllum L. (Haloragaceae) in Taiwan. Taiwania 41: 322-328.

Liu F, Zhang S, Wang Y, et al. 2016. Nitrogen removal and mass balance in newly-formed Myriophyllum aquaticum mesocosm during a single 28-day incubation with swine wastewater treatment. $J$ Environ Manag 166: 596-604.

Ning D, Huang Y, Pan R, et al. 2014. Effect of eco-remediation using planted floating bed system on nutrients and heavy metals in urban river water and sediment: a field study in China. Sci Total Environ 485-486: 596-603.

Qu J, Fan M. 2010. The current state of water quality and technology development for water pollution control in China. Crit Rev Environ Sci Technol 40: 519-560.

Saunkaew P, Wangpakapattanawong P, Jampeetong A. 2011. Growth, morphology, ammonium uptake and nutrient allocation of Myriophyllum brasiliense Cambess. under high $\mathrm{NH}_{4}^{+}$concentrations. Ecotoxicology 20: 2011-2018.
Scheffer M, Hosper SH, Meijer ML, et al. 1993. Alternative equilibria in shallow lakes. Trends Ecol Evol 8: 275.

SEPA. 2002. Analytical methods for water and wastewater monitor, 4th ed. Beijing: Chinese Environmental Science Press (in Chinese).

Souza FA, Dziedzic M, Cubas SA, et al. 2013. Restoration of polluted waters by phytoremediation using Myriophyllum aquaticum (Vell.) Verdc., Haloragaceae. J Environ Manage 120: 5-9.

Thiébaut G. 2007. Invasion success of non-indigenous aquatic and semi-aquatic plants in their native and introduced ranges. A comparison between their invasiveness in North America and in France. Biol Invasions 9: 1-12.

Thiébaut G, Martinez L. 2015. An exotic macrophyte bed may facilitate the anchorage of exotic propagules during the first stage of invasion. Hydrobiologia 746: 183-196.

Wang Z, Zhang Z, Zhang Y, et al. 2013. Nitrogen removal from Lake Caohai, a typical ultra-eutrophic lake in China with large scale confined growth of Eichhornia crassipes. Chemosphere 92: 177-183.

Wersal RM, Madsen JD. 2011. Influences of water column nutrient loading on growth characteristics of the invasive aquatic macrophyte Myriophyllum aquaticum (Vell.) Verdc. Hydrobiologia 665: 93-105.

Xie D, Yu D, Yu LF, et al. 2010. Asexual propagations of introduced exotic macrophytes Elodea nuttallii, Myriophyllum aquaticum, and M. propinquum are improved by nutrient-rich sediments in China. Hydrobiologia 655: 37-47.

Zhang X, Liu Z. 2011. Interspecific competition effects on phosphorus accumulation by Hydrilla verticillata and Vallisneria natans. J Environ Sci 23: 1274-1278.

Zhang L, Wang S, Jiao L, et al. 2013. Physiological response of a submerged plant (Myriophyllum spicatum) to different $\mathrm{NH}_{4} \mathrm{Cl}$ concentrations in sediments. Ecol Eng 58: 91-98.

Zhang S, Liu F, Xiao R, et al. 2017. Nitrogen removal in Myriophyllum aquaticum wetland microcosms for swine wastewater treatment: ${ }^{15} \mathrm{~N}$-labelled nitrogen mass balance analysis. $J$ Sci Food Agric 97: 505-511.

Cite this article as: Tan B, He H, Gu J, Li K. 2018. Eutrophic water or fertile sediment: which is more important for the growth of invasive aquatic macrophyte Myriophyllum aquaticum? Knowl. Manag. Aquat. Ecosyst., 419, 3. 